\title{
Visão do Setor Supermercadista em Relação aos Produtos com Registro da Indicação de Procedência dos Vales da Uva Goethe
}

\author{
View of the Supermarket Sector in Relation to Products with Record of \\ Indicação de Procedência dos Vales da Uva Goethe
}

\author{
Arthur Coan ${ }^{1}$ \\ Adriana Carvalho Pinto Vieira ${ }^{2}$ \\ Michele Domingos Schneider ${ }^{1}$ \\ Julio Cesar Zilli ${ }^{1}$ \\ ${ }^{1}$ Universidade do Extremo Sul Catarinense, Criciúma, SC, Brasil \\ ${ }^{2}$ Instituto Nacional de Ciência e Tecnologia em Políticas Públicas Estratégias e Desenvolvimento, Rio de Janeiro, RJ, Brasil
}

\begin{abstract}
Resumo
Os Vales da Uva Goethe são uma região produtora de Uva e Vinho localizada no Sul de Santa Catarina, compreendendo oito municípios. Em 2012, essa produção conquistou o registro de Indicação de Procedência Vales da Uva Goethe. Diante do exposto, o presente estudo objetivou identificar a visão do setor supermercadista em relação aos vinhos produzidos com o registro de Indicação de Procedência dos Vales da Uva Goethe na cidade de Criciúma - SC. Metodologicamente, esta pesquisa caracterizou-se como descritiva quanto aos fins e de campo quanto aos meios de investigação. A população-alvo foi delimitada pelos supermercados da cidade de Criciúma $\mathrm{SC}$, caracterizadas pelos sommeliers ou responsáveis pela compra de vinhos do estabelecimento. Verificou-se que os sommeliers sabem o que é Indicação Geográfica, ao contrário dos consumidores. Os vinhos e espumantes dos Vales da Uva Goethe são comercializados em $50 \%$ dos supermercados. Apesar de o consumo de vinhos nacionais crescer, o consumidor tem preferência pelos importados, principalmente os chilenos.
\end{abstract}

Palavras-chaves: Comportamento do Consumidor. Supermercados. Indicação Geográfica.

\begin{abstract}
The Vales da Uva Goethe is a Grape and Wine producing region located in the south of Santa Catarina, comprising eight municipalities. In 2012, he won the Indicação de Procedência dos Vales da Uva Goethe. The present study aimed to identify the vision of the supermarket sector in relation to the wines produced with the record of Indication of Origin of Goethe Grapes in the city of Criciúma - SC. Methodologically, it was characterized as a descriptive research, regarding the ends and field research as to the means of investigation. The target population was delimited by the supermarkets of the city of Criciúma-SC, characterized by sommeliers or responsible for buying wines from the establishment. It has been found that sommeliers know what Geographical Indication is, unlike consumers. The wines and sparkling wines of the Goethe Grape Vales are sold in 50\% of the supermarkets. Although the consumption of national wines grows, the consumer has preference for the imported ones, mainly the chileans.
\end{abstract}

Keywords: Consumer Behavior. Supermarkets. Geographical Indication.

Área Tecnológica: Indicações Geográficas. 


\section{Introdução}

De acordo com o Instituto Brasileiro do Vinho (IBRAVIN, 2017b), o consumo per capita de vinho no Brasil representa um dos maiores mercados inexplorados para os vinhos, possuindo apenas 2,56 litros per capita em 2015, enquanto em outros países, como a França, há um consumo de 52,23 litros per capita. Portugal tem um consumo de 48,17 litros per capita e a Itália tem um consumo de 46,51 litros per capita. Esse relatório apresenta, também, que os vinhos produzidos nacionalmente continuaram a dominar o mercado brasileiro, embora ainda exista um grupo grande de consumidores que acreditam que os vinhos importados são superiores. No entanto, esse paradigma tem sido quebrado quando se percebe o sucesso que fazem as espumantes das marcas brasileiras.

Nos últimos três anos, o consumo de vinhos finos teve um elevado crescimento, chegando a $71 \%$, enquanto os comuns tiveram aumento de $23 \%$, isso pode ter se caracterizado pelo fato de as classes sociais no Brasil terem ascendido, decorrente de uma economia mais estabilizada (TERROIRS, 2016).

O Estado de Santa Catarina aparece como o sexto maior produtor de uva do Brasil, atrás dos Estados do Rio Grande do Sul, São Paulo, Pernambuco, Paraná e Bahia, respectivamente. A produção estadual de vinhos e de suco de uva somou, em 2010, um total de 13,5 milhões de litros (DUARTE, 2013).

O município de Urussanga, no Sul de Santa Catarina, é conhecido como a Capital Catarinense do Bom Vinho. Essa região viveu seu auge na década de 1940. Entretanto, com o advento da mineração muitos vitivinicultores deixaram de seguir no ramo para se dedicar ao trabalho nas minas de carvão em razão dos salários mais atraentes nas minas e da promessa de aposentadoria após 15 anos (VIEIRA; WATANABE, BRUCH, 2012). Dessa forma, muitas vinícolas de Urussanga fecharem suas portas.

Urussanga produzia nessa época um vinho branco que era chamado de Vinho Branco de Urussanga, que, na verdade, era o vinho da uva Goethe. Segundo Vieira, Watanabe e Bruch (2012), os vinhos brancos de Urussanga fizeram sucesso ao longo do tempo, e um dos apreciadores desse vinho foi o presidente brasileiro Getúlio Vargas, que, além de indicar o vinho como o vinho oficial do Palácio do Catete à época, em 1945, autorizou a instalação de uma estação de enologia na região.

Os vinhos e espumantes da uva Goethe receberam o registro da Indicação de Procedência dos Vales da Uva Goethe, conforme consta na Revista de Propriedade Industrial n. 2.145, de 14 de fevereiro de 2012, na forma de signo nominativo, para vinho branco seco, suave ou demi-sec, leve branco seco, suave ou demi-sec, vinho espumante brut ou demi-sec obtidos pelo método "Champenoise" e pelo método "Charmat", vinho licoroso. Compreende a seguinte área delimitada: Vales da Uva Goethe, localizada entre as encostas da Serra Geral e o litoral sul catarinense nas Bacias do Rio Urussanga e Rio Tubarão, compreendendo os municípios de Urussanga, Pedras Grandes, Cocal do Sul, Morro da Fumaça, Treze de Maio, Orleans, Nova Veneza e Içara no Estado de Santa Catarina, Brasil (VIEIRA; WATANABE; BRUCH, 2012).

Hansen e Rossi (2008), em estudo realizado, verificaram que a distribuição de vinhos no Brasil ocorre principalmente pelos supermercados e que, por não possuir barreiras de entrada, os vinhos importados competem diretamente com os vinhos nacionais. 
Apesar de existirem lojas especializadas, os vinhos ainda são muito comercializados em supermercados, embora sejam um importante canal de distribuição de produtos.

Diante do que foi exposto, ressalta-se que o estudo tem por objetivo identificar qual a visão do setor supermercadista em relação aos produtos com registro da Indicação de Procedência dos Vales da Uva Goethe na cidade de Criciúma - SC.

\subsection{Segmentação e Posicionamento de Mercado}

Smith (1956) compara a diferenciação de produto com a segmentação de mercado, e a sua análise está baseada no desenvolvimento pelo olhar da procura do mercado. A partir desse cenário, há a necessidade de realizar ajustes para oferecimento do produto nos mercados e dos esforços de marketing para conquistar os consumidores. $\mathrm{O}$ autor defende também a importância do aparecimento da segmentação como uma estratégia, partindo de um mercado heterogêneo, caracterizado por diferentes necessidades de consumidores que são catalogadas como pequenos mercados homogêneos numa resposta às múltiplas preferências de produtos (SMITH, 2016).

Para Lamb, Hair Jr. e McDaniel (2004), a segmentação de mercado é uma estratégia muito interessante para as empresas, pois os consumidores possuem preferencias diferenciadas $e$ agrupar um grupo de compradores com as mesmas características é muito importante. Tavares, Afonso e Locatelli (2011) orientam que segmentar um mercado traz algumas utilidades práticas, como: em qual segmento a empresa deve focar e a identificação das possibilidades de mercado.

Portanto, pode ser inferido que as vantagens da segmentação do mercado, dá a possibilidade para as empresas, além de perceber o mercado sob o olhar do cliente. No entanto, ao mesmo tempo, também pode explorar seus pontos fortes, selecionar melhor os seus segmentos compatíveis com a sua estrutura. E, ainda pode desenvolver estratégias diante das exigências do mercado e identificar as suas lacunas que oferecem oportunidades para o lançamento de novos produtos. Dessa forma, identificando o perfil do segmento de mercado, é possível comunicar-se com o consumidor que se encaixa em um determinado perfil de consumo.

Após definido o mercado em que irá atuar, a empresa precisa decidir qual o posicionamento adotará para os seus produtos.

Kotler (1998) define posicionamento de mercado como a forma com a qual o produto é definido pelos seus consumidores, quanto aos seus atributos mais importantes. É um complexo grupo de percepções, impressões e sentimentos dos consumidores sobre um produto com relação aos produtos concorrentes.

Kotler e Keller (2006) destacam que o posicionamento de um produto não é o que a empresa faz com ele, mas sim o que o produto faz na mente do cliente potencial. As disparidades $e$ as afinidades entre as marcas devem ser definidas para se criar um posicionamento entre elas.

\subsubsection{Comportamento do Consumidor}

Compreender o comportamento do consumidor é importante para as empresas, a fim de identificar quem participa do processo de decisão de compra e quem influência nessa decisão, identificando culturas, valores, crenças e desejos que influenciam na decisão (KOTLER, 1998). 
Para Las Casas (2005), num processo de compra mais complexo, o consumidor leva mais tempo para adquirir o produto, já que ele leva em consideração alguns aspectos, como qualidade, comparativo de preços e ofertas de mercado, para decidir se realmente o produto irá trazer os benefícios percebidos.

$\mathrm{E}$, existem alguns estágios no momento da decisão de compra, entre eles: reconhecimento da necessidade, busca de informação, avaliação das alternativas, decisão de compra, comportamento pós-compra.

No reconhecimento da necessidade, o consumidor irá avaliar se realmente o produto que ele deseja é necessário ou se é um estímulo causado por uma propaganda, por exemplo.

A busca por informação trata de informar sobre as características dos produtos que o consumidor deseja ou necessita.

Após essas duas etapas, o consumidor irá avaliar, conforme suas informações, as alternativas entre os produtos que ele deseja ou necessita e decidir aquele que irá satisfazê-lo.

E o comportamento pós-compra está ligado à expectativa que o consumidor criou em relação ao produto ou serviço. Por exemplo, se ele criou uma expectativa baixa em relação a um carro usado que teve um ótimo desempenho, sua expectativa será superada (KOTLER; KELLER, 2006).

\subsubsection{A Percepção do Consumidor com Relação ao Preço Pago pelo Produto e à Agregação de Valor}

Conforme pondera Passerini (2011), a agregação de valor é um balizador de diferenciação do produto no mercado, seja por meio de um aumento na matéria-prima, a qualidade na produção, as inovações tecnológicas sejam pelas demais vantagens do produto em si.

Agrega-se valor a um produto quando se consegue chamar a atenção de um conjunto de consumidores, e isso pode ser alcançado de diversas formas, como: a) diversidade - existe inúmeras maneiras de se oferecer um produto: pela cor, modelo, formas e quantidades e, certamente, algumas dessas opções agradarão o consumidor; b) Imagem - há a necessidade de saber associar a imagem do produto ao público especifico, fazendo com que os consumidores olhem com bons olhos o que querem adquirir; c) Ecologia - produtos que utilizam matérias recicláveis e utilizam processos ambientalmente corretos têm despertado interesse diferenciado nos consumidores; d) Garantia estendida - nesse caso, há uma segurança presumida na hora da compra, fazendo com que mais consumidores paguem por esse serviço para minimizar o risco de prejuízos em decorrência de defeitos de produtos (COELHO; FOLLMANN; RODRIGUEZ, 2008).

Segundo Vázquez (2007), esse tipo de comunicação é uma forma eficaz de diferenciação para fidelizar o público, já que, no setor empresarial, hoje se manifesta uma preocupação em gerenciar as emoções de maneira adequada.

$\mathrm{O}$ valor percebido pelo cliente está diretamente relacionado com a percepção que ele tem do produto. A sua utilidade é importante, mas a sensação de estar comprando algo que vá diferenciá-lo das outras pessoas e, principalmente, de poder obtê-lo no momento em que decidir comprá-lo, a um preço compatível, faz toda a diferença (COELHO; FOLLMANN; RODRIGUEZ, 2008). 
Para Ribeiro (2005), os consumidores costumam escolher produtos que lhes oferecem maior valor. Portanto, para manter os clientes e conquistar os novos, é imperativo compreender as suas necessidades e os processos de compra de uma maneira mais eficaz do que os concorrentes no mercado.

\subsection{Potencial de Mercado}

Economicamente falando, segundo Pindyck e Rubinfeld (2016), o mercado é divido em dois grandes grupos, que são os compradores e os vendedores. Os compradores são os consumidores que adquirem bens e serviços e as empresas que adquirem matérias-primas, mão de obra para produção de bens e serviços. Já no grupo dos vendedores se enquadram os trabalhadores que vendem sua mão de obra, os proprietários de recursos.

Dessa forma, Pindyck e Rubinfeld (2016, p. 8) concluem que: “[...] um mercado é, portanto, um grupo de compradores e vendedores, que por meio de suas interações efetivas ou potenciais, determinam o preço de um produto".

Para um produto permanecer no mercado, ele precisa atender às necessidades dos clientes. Os concorrentes e os consumidores encontram-se em constante mutação, ou melhor, mudanças, exigindo, dessa forma, estratégias de posicionamento de mercado para se diferenciarem de seus concorrentes. Essa distinção tende a estimular aqueles que conseguem se adequar melhor às necessidades dos clientes e, consequentemente, podem se manter pelo maior tempo possível no mercado (REIS, 2007).

\subsection{Mercado de Vinhos}

O mercado de vinhos vem enfrentando modificações ao longo dos anos. Até a década de 1980 ocorri um declínio no consumo de vinhos e esse declínio teria se acentuado ainda até meados da década de 1990 (SATO; ANGELO, 2007). Diante desse cenário, como apontam Protas, Camargo e Melo (2013), foi a partir da década de 1980 que as vinícolas, principalmente as localizadas no sul do Brasil, deram início a um intenso investimento em tecnologia e em inovações para a produção de uvas europeias, além disso, também iniciaram processos de vinificação modernos comparados aos países de primeiro mundo. Tal fato tem contribuído de forma gradativa para a melhor qualidade do vinho nacional nas últimas décadas.

Teruchkin (2003) ressalta que a mudança no mercado de vinho até a década de 1990 poderia estar condicionada à questão da oferta e da demanda. Para o autor, uma das principais mudanças ocorridas nesse período pode ser em função da redução do consumo de vinhos comuns nos principais países consumidores do produto, abrindo espaço, dessa forma, para o consumo de vinhos finos (TERUCHKIN, 2003).

Em estudo realizado no mercado do Distrito Federal, por meio de aplicação de questionários, observou-se que as indicações geográficas são um fator de diferenciação de produto, agregando valor aos vinhos. Nessa pesquisa, foi identificado que $57 \%$ dos consumidores estariam dispostos a pagar valores mais altos por vinhos que contivessem o selo de indicação geográfica. Em resposta a essa oportunidade de mercado, as vinícolas brasileiras têm procurado investir em registros de indicações geográficas como um instrumento de qualidade para o consumidor. A partir desse cenário, algumas vinícolas nacionais tomaram iniciativas nesse sentido (GLASS; CASTRO, 2009). 


\subsection{Indicação Geográfica}

A Organização das Nações Unidas para a Agricultura e a Alimentação (FAO, 2010) define a Indicação Geográfica (IG) como o nome de um lugar, ou país, que identifica um produto cuja qualidade, reputação ou outras características são imputáveis a sua origem. Dessa forma, segundo a organização, a IG sinaliza aos consumidores que os produtos com esse registro exibem características especiais devido à sua origem geográfica (FAO, 2010).

Segundo o Instituto Nacional da Propriedade Industrial (INPI, 2017), “[...] a Indicação Geográfica (IG) é usada para identificar a origem de produtos ou serviços quando o local tenha se tornado conhecido ou quando determinada característica ou qualidade do produto ou serviço se deve a sua origem".

No Brasil, a IG possui duas classificações: indicação de procedência e denominação de origem. A indicação de procedência refere-se ao nome do local que se tornou conhecido por produzir, extrair ou fabricar determinado produto ou prestar determinado serviço. Já a denominação de origem refere-se ao nome do local que passou a designar produtos ou serviços, cujas qualidades ou características podem ser atribuídas a sua origem geográfica (INPI, 2015).

Oliveira e Wehrmann (2013) destacam que as IGs podem ser concebidas como uma ferramenta de desenvolvimento econômico e de política agrícola para aprimorar meios de desenvolvimento sustentável da agricultura e do extrativismo vegetal, com vistas à geração de emprego e renda e para a fixação do homem no campo.

De acordo com a Associação dos Produtores de Vinhos Finos do Vale dos Vinhedos (APROVALE, 2017), estas são algumas repercussões de caráter mercadológico que aconteceram na Região do Vale dos Vinhedos após a concessão do registro de IG: a) o aumento do valor agregado dos produtos e/ou a geração de maior facilidade de colocação no mercado, sendo assim, os produtos ficam menos sujeitos à concorrência com outros produtos de preço e qualidade inferiores; b) a melhora do produto, tornando mais estável a sua demanda, pois gera confiança no consumidor, que, sob a etiqueta da indicação geográfica, sabe que vai encontrar um produto de qualidade e com características regionais; c) a possibilidade de o consumidor identificar perfeitamente o produto entre outros, inclusive de preços inferiores; d) a oportunidade de criar mecanismos legais contra fraudes e usurpações, facilitando a ação contra o uso indevido da indicação geográfica.

\subsection{Vales da Uva Goethe}

Os Vales da Uva Goethe estão localizados entre as encostas da Serra Geral e o litoral sul catarinense nas Bacias do Rio Urussanga e do Rio Tubarão. Compreende os municípios de Urussanga, Pedras Grandes, Cocal do Sul, Morro da Fumaça, Treze de Maio, Orleans, Nova Veneza e Içara no Estado de Santa Catarina, Brasil (VALES DA UVA GOETHE, 2013).

Quando os primeiros imigrantes italianos chegaram para colonizar a cidade de Urussanga, eles trouxeram algumas variedades de uvas europeias, porém, elas não se adaptaram ao solo e ao clima do local. Diante desse cenário, foram realizadas várias tentativas de plantio de uvas americanas e a variedade Goethe foi a que acabou se adaptando melhor à região (VIEIRA; WATANABE; BRUCH, 2012). 
Como a variedade Goethe se adaptou muito bem à região de Urussanga, a atividade da vitivinicultura cresceu, aumentando a produção e, consequentemente, a comercialização dos vinhos, chegando até a ser servido no Palácio do Catete, sede do governo de Getúlio Vargas no Rio de Janeiro, como vinho oficial (VALES DA UVA GOETHE, 2013). Segundo Velloso (2008), foram estabelecidos oito vinícolas em Urussanga, com a maior produção de vinho no estado à época, recebendo o título de capital catarinense do vinho. Com a ideia de fortalecer a produção do vinho e da uva Goethe em Urussanga, foi criada, em 2005, a Associação dos Produtores da Uva e do Vinho Goethe (VALES DA UVA GOETHE, 2013).

Com auxílio do Serviço Brasileiro de Apoio às Micros e Pequenas Empresas (SEBRAE), a Empresa de Pesquisa Agropecuária e Extensão Rural de Santa Catarina (EPAGRI) e a Universidade Federal de Santa Catarina (UFSC) elaboram um dossiê com os dados para solicitação do registo de indicação geográfica junto ao Instituto Nacional da Propriedade Industrial (INPI) (VELLOSO, 2008).

Como apontam Vieira e Pellin (2015), a Indicação de Procedência dos Vales da Uva Goethe (IPVUG) foi concedida em 2012, foi o primeiro registro para o Estado de Santa Catarina até os dias atuais, publicado na Revista de Propriedade Industrial do INPI, sob n. 2.145, em 14 de fevereiro (VIEIRA; WATANABE, BRUCH, 2012).

\subsection{Setor Supermercadista}

A notoriedade do setor supermercadistas está se tornando cada vez mais representativo na economia brasileira. O setor supermercadista brasileiro registrou faturamento de $\mathrm{R} \$ 338$, 7 bilhões em 2016, um crescimento nominal de 7,1\% na comparação com 2015. O resultado registrado em 2016 pelo setor representa 5,4\% do Produto Interno Bruto (PIB) no Brasil (ABRAS, 2017).

Pacheco (2017) ressalta que a cidade de Criciúma é historicamente um polo regional de Santa Catarina em relação ao empreendedorismo e ao desenvolvimento de empresas varejistas supermercadistas com relevância e sucesso, tanto no âmbito estadual como nacional. Possui duas grandes redes supermercadistas entre as demais instaladas na cidade e região de tamanho e importância relevantes que estão entre as 25 maiores empresas do setor do país. Em Santa Catarina, o setor supermercadista emprega mais de 75 mil funcionários, possuindo mais de 2.200 estabelecimentos comerciais. Em 2016, o setor teve um aumento de 1,14\% nas vendas, estando acima da inflação, de acordo com dados da Associação Catarinense de Supermercados (ACATS, 2017). Pacheco (2017) destaca que a potência desse setor é fonte de geração de emprego, renda e de desenvolvimento das regiões onde estão inseridos.

\section{Procedimentos Metodológicos}

Quanto aos fins, a presente pesquisa se caracteriza como descritiva. Na pesquisa foi utilizado esse método por meio do levantamento de dados junto ao sommelier ou ao funcionário responsável pelo setor de vinhos dos supermercados estudados na região de Criciúma - SC. Com propósito de verificar qual a aceitação dos supermercados em relação à venda de vinhos Goethe com o registro de IG da região delimitada da Indicação de Procedência dos Vales da Uva Goethe. Quanto aos meios de investigação, foi utilizada a pesquisa de campo de forma que 
foi realizada a aplicação de questionário estruturado, via Google Docs, com o sommelier ou o funcionário responsável pelo setor de vinhos dos supermercados de Criciúma - SC.

Foi selecionada a cidade de Criciúma - SC por ser a maior cidade próxima à região delimitada da Indicação de Procedência dos Vales da Uva Goethe, com aproximadamente 211 mil habitantes. A cidade também é sede de três dos 25 maiores supermercados do Estado de Santa Catarina. Dessa forma, o questionário foi enviado para seis supermercados de Criciúma em decorrência da acessibilidade. Desses seis estabelecimentos, somente quatro responderam. Para o presente estudo, foi utilizada a abordagem qualitativa para se atingir o objetivo de identificar a aceitação dos vinhos produzidos com o selo de Indicação de Procedência dos Vales da Uva Goethe pelo setor supermercadista na cidade de Criciúma - SC.

\section{Análise dos Dados: percepção do comportamento do consumidor referente à indicação geográfica}

O primeiro ponto a ser analisado na pesquisa foi identificar o conhecimento do sommelier ou do funcionário do setor de vinho do supermercado em relação à Indicação Geográfica e à percepção que ele possui sobre seu consumidor. Portanto, a primeira pergunta identificou se o sommelier conhece o conceito de Indicação Geográfica. Foi possível perceber que todos os sommeliers mostraram conhecimento sobre o conceito do que é uma Indicação Geográfica. Esse fato corrobora com a pesquisa realizada pelo Ibravin (2008), a qual identifica que um dos principais fatores que influenciam o consumidor na escolha de um vinho é o sommelier. Portando, o sommelier, ou o funcionário do setor do vinho, ter conhecimento do que é uma IG é fundamental para que o consumidor possa optar por esse tipo de vinho.

A segunda pergunta foi se o sommelier possui a percepção de que o seu consumidor também tenha esse conhecimento. A partir dos dados da pesquisa, pode-se perceber que, na percepção do sommelier dos supermercados, a maior parte dos consumidores de Criciúma (75\%) não possui o conhecimento do que é uma Indicação Geográfica. Constatou-se que apenas 25\% têm conhecimento do que é uma IG.

Esse fato se confirma com o que Maiorki e Dallabrida (2015) apontam ao dizerem que o maior problema nas relações de consumo está no aspecto de que o consumidor brasileiro tem pouca informação sobre o que significa um produto ter registro de uma IG e, principalmente, que esses produtos são controlados a partir de normas estabelecidas pelo Conselho Regulador, dispostas no Manual de Uso (algumas IGs podem denominar de Caderno de Uso).

\subsection{Comercialização de Vinhos e Espumantes com Indicação Geográfica}

O segundo ponto analisado na pesquisa foi identificar se os supermercados pesquisados comercializam vinhos e espumantes com Indicação Geográfica, quais são, quanto isso representa do total do volume de compra de vinhos e se possui vinhos e espumantes da Indicação de Procedência Vales da Uva Goethe. Percebeu-se que todos os supermercados possuem vinhos com registro de Indicação Geográfica nos seus estabelecimentos. Assim como em outros segmentos alimentares, os supermercados se tornaram um componente central da cadeia de valor, 
contribuindo para redefinir as tendências de consumo e de produção. Nierdele (2011) aponta em seus estudos que $65 \%$ dos consumidores compram vinhos nos supermercados.

Uma vez que na primeira questão foi constatado que os supermercados comercializam vinhos e espumantes com registro de Indicação Geográfica, a próxima pergunta buscou identificar quais são as IGs comercializadas.

Gráfico 1 - IGS comercializadas

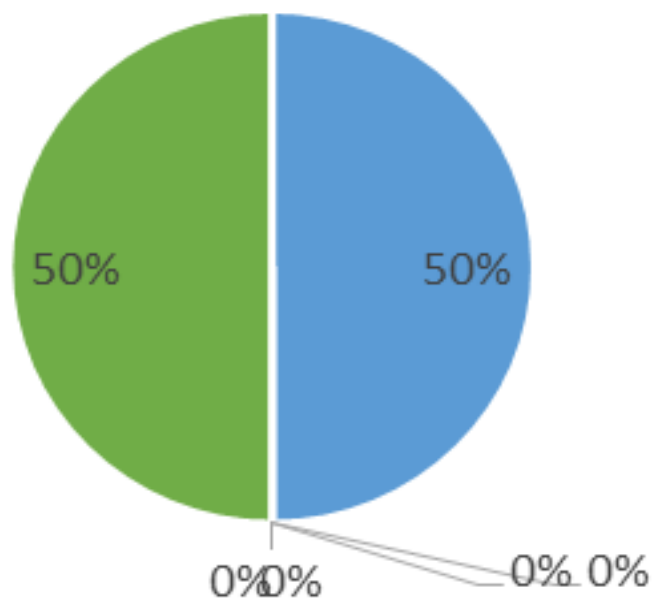

- Vale dos Vinhedos

- Pinto Bandeira

Monte Belo

- Farroupilha

- Altos Montes

- Vales da Uva Goethe

Fonte: Dados da pesquisa (2017)

Pelos dados do Gráfico 1, verifica-se que, das sete Indicações Geográficas existentes no Brasil, os supermercados comercializam somente duas: vinhos do Vale dos Vinhedos (Indicação Geográfica no Estado do Rio Grande do Sul) e da catarinense vinhos dos Vales da Uva Goethe (Indicação Geográfica do Estado de Santa Catarina). De acordo com dados da Universoagro (2014), aproximadamente 65\% do vinho produzido pela Indicação de Procedência dos Vales da Uva Goethe são comercializados em Santa Catarina. Ainda, nota-se que, na maior parte dessa porcentagem, as vendas ocorrem nas próprias vinícolas, diretamente para os consumidores, $e$ uma pequena parte em redes de supermercados.

Os Vales dos Vinhedos em decorrência de ser a primeira IG brasileira (inclusive a do setor dos vinhos) já possuem maior experiência na questão de comercialização de seus produtos $e$ buscam por novos mercados, com marcas já consolidadas no mercado nacional e internacional. Possuem cerca de 30 vinícolas e 41 empreendimentos voltados à cultura do vinho e paisagens da região.

A próxima questão buscou identificar a porcentagem do volume total da compra de vinhos da empresa com registro de uma Indicação Geográfica. O reflexo das poucas IGs comercializadas pelos supermercados mostra que, a partir dos dados da pesquisa, $75 \%$ dos supermercados compram apenas de $10 \%$ a $20 \%$ de vinhos e espumantes com IG do total adquirido do produto. E apenas $25 \%$ dos supermercados comercializam de $31 \%$ a $40 \%$.

\subsection{Comercialização de Vinhos e Espumantes dos Vales da Uva Goethe}

Este bloco buscou identificar se os supermercados comercializam vinhos e espumantes que possuem o registro da Indicação de Procedência dos Vales da Uva Goethe e descobrir quais os produtos e em quais vinícolas são comercializados. 
Gráfico 2 - Comercialização de vinhos e espumantes da IPVUG

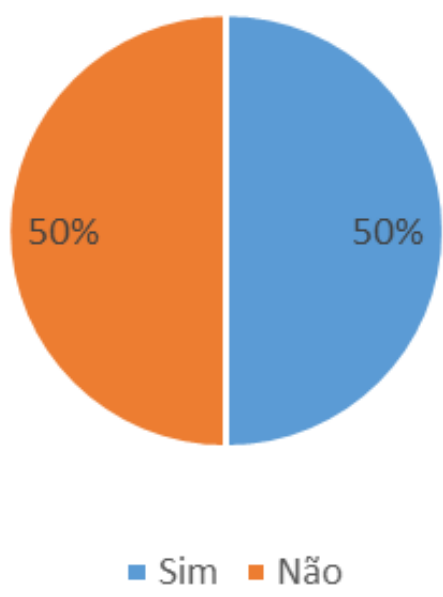

Fonte: Dados da pesquisa (2016)

Conforme pode ser observado no Gráfico 2, metade dos sommeliers ou dos funcionários dos supermercados informou que, na sua empresa, eles comercializam vinhos e espumantes que contêm registro da Indicação de Procedência dos Vales da Uva Goethe.

A pergunta seguinte buscou identificar, entre os vinhos e espumantes com registro da IPVUG, de quais vinícolas são comercializados os produtos.

Gráfico 3 - Vinícolas da IPVUG comercializadas

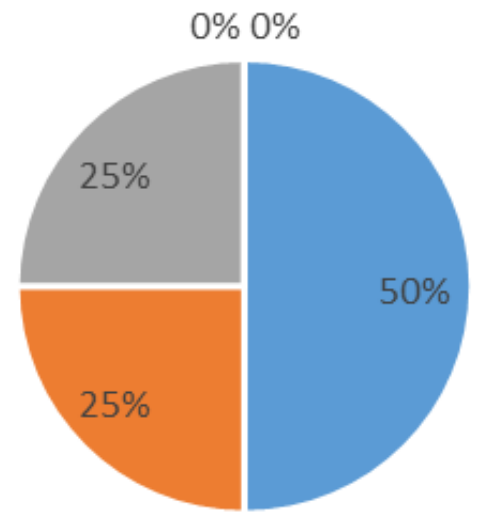

- Vitivinícola Urussanga (Casa Del Nonno)

- Vinícola Mazon

- Vinícola Quarezemin

- Vinícola Trevisol

- Vinícola De Nonni

Fonte: Dados da pesquisa (2016)

Percebeu-se que, dos supermercados que comercializam vinhos e espumantes com registro da Indicação de Procedência dos Vales da Uva Goethe, todos eles (100\%) vendem produtos da Vitivinícola Urussanga (Casa Del Nonno) e 50\% vendem da Vinícola Quarezemin e Vinícola Mazon.

De acordo com os dados apresentados, apenas uma parcela dos produtos com registro da IPVUG é comercializada em supermercados. Dessa forma, pelos dados do Gráfico 3 constata-se que a Vitivinícola Urussanga detém a maior porcentagem de comercialização de vinhos e espumantes nos supermercados entrevistados, seguida da Vinícola Quarezemin e Vinícola Mazon. No entanto, conforme já mencionado, as maiores porcentagens das vendas para as vinícolas estão 
concentradas no próprio estabelecimento comercial, seguidas dos supermercados, restaurantes e outros postos de vendas (DAMIAN, 2006).

A oitava pergunta avaliou se os supermercados possuem um local exclusivo para comercializarem vinhos e espumantes com Indicação Geográfica. Embora a Indicação Geográfica valorize os produtos, nenhum dos supermercados possuem um local exclusivo para comercializar vinhos e espumantes com Indicação Geográfica, ou para qualquer outro tipo de produto que tenha um registro de IG.

Para se obter vantagem competitiva, uma empresa deve desenvolver um conjunto de diferenças significativas em seus produtos ou serviços que destaque as vantagens com relação aos produtos ou serviços oferecidos pelos concorrentes. Sugere-se que isso se faça por meio de uma estratégia de posicionamento que vem a ser a forma como o consumidor percebe e avalia uma determinada empresa ou produto (KOTLER, 1998).

\title{
3.3 Tipos de Vinhos e Espumantes Adquiridos pelos Consumidores do Setor Supermercadista do Município de Criciúma - SC
}

Neste bloco buscou-se identificar quais os tipos de vinhos e espumantes são adquiridos pelos consumidores na percepção do sommelier ou funcionário do setor de vinhos.

Gráfico 4 - Tipos de vinhos adquiridos

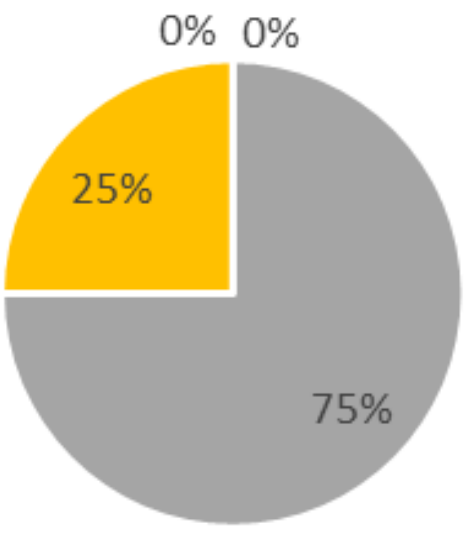

\author{
- Vinho/espumante \\ nacional \\ - Vinho/espumante \\ nacional com IG \\ - Vinho/espumante \\ importado \\ - Vinho/espumante \\ importado com IG
}

Fonte: Dados obtidos pela pesquisa (2017)

Pode-se verificar a partir dos dados do Gráfico 4 que $75 \%$ das vendas são de vinhos importados e $25 \%$ de vinhos importados com Indicação Geográfica. Segundo dados da Ibravin (2017a), houve um aumento de 40\% na entrada de vinhos importados no Brasil, e o desempenho do vinho nacional recuou $10 \%$.

\subsection{Preferência dos Consumidores de Vinho ou Espumante do Setor Supermercadista do Município de Criciúma - SC}

De acordo com os dados da pesquisa, buscou-se identificar qual é a preferência do consumidor em relação aos vinhos vendidos na região de Criciúma - SC. 
Todos os respondentes (100\%) informaram que os vinhos de maior preferência dos consumidores são os vinhos chilenos. Segundo o blog Meu Vinho (2017), os brasileiros aumentaram o consumo de vinhos chilenos em 2016 e novamente o Chile fechou o ano liderando com folga o ranking de vinhos importados no Brasil. Apesar da preferência por vinhos importados, a venda de vinhos nacionais cresceu 4,3\% em 2015, e isso se deve a um grande esforço das empresas brasileiras em primar pela melhor qualidade de seus produtos para que tenham mais competitividade no mercado nacional e internacional (IBRAVIN, 2015).

\subsection{Análise Geral da Pesquisa}

A partir dos dados obtidos, constata-se que todos os sommeliers têm conhecimento do que é uma Indicação Geográfica (IG). Isso é um fato muito importante, pois os sommeliers são os responsáveis pelas compras dos vinhos e, muitas vezes, são eles que esclarecem as dúvidas dos consumidores. Em contrapartida, sob a visão deles, muitos consumidores não têm o conhecimento do que é uma IG, o que demonstra que ainda há muito o que se fazer para que os consumidores tenham mais informações dos vinhos registrados com IGs no Brasil. Os consumidores estão em constantes mudanças, o que exige estratégias diferenciadas para posicionar seus produtos e, dessa forma, se diferenciar de seus concorrentes (REIS, 2007).

Ainda, a partir dos dados da pesquisa, se constatou que todos os supermercados comercializam vinhos e espumantes com IG. Embora haja comercialização de vinhos e espumantes com IG, somente são comercializados dois tipos: Vales dos Vinhedos e Vales da Uva Goethe no município de Criciúma - SC, região foco do estudo do presente trabalho.

Segundo a Aprovale (2017), o Vale dos Vinhedos obteve o registro de IG em 2002, podendo conceder aos vinhos que estivessem dentro dos padrões estabelecidos pela Associação (de acordo com as normas do Conselho Regulador) o selo de Indicação de Procedência (IP). A partir de 2012, há o reconhecimento da Denominação de Origem (DO) para os produtos que estejam de acordo com novo Manual de Uso do novo Conselho Regulador e que deverão obedecer a regras mais específicas em relação à produção da uva e à elaboração do vinho na região.

Já os Vales da Uva Goethe é uma IG recente, visto que seu registro foi concedido em 2012. Atualmente está na quarta safra e tem o controle do Conselho Regulador a partir das normas estabelecidas no Manual de Uso. A partir dos dados de pesquisa constatados, dos supermercados entrevistados, há em $50 \%$ deles produtos advindos da região da IPVUG, e a Vitivinícola Urussanga está em todos eles, apesar de sua estratégia se concentrar principalmente no próprio estabelecimento (75\%), ela está em $50 \%$ dos supermercados pesquisados. Conforme dito por Vieira e Pellin (2015), as vendas dos vinhos da IPVUG cresceram $20 \%$ e a de espumantes $30 \%$ após a conquista do registro, principalmente no próprio estabelecimento dos produtores de vinho da região da IPVUG.

Embora todos os supermercados comercializem vinhos e espumantes com IG, o volume de compra de vinhos e espumantes com esse registro ainda é baixo em relação ao total comprado, visto que $75 \%$ dos supermercados compram apenas de $10 \%$ a $20 \%$ do volume total $e$ $25 \%$ dos supermercados compram de $31 \%$ a $40 \%$, o que é um bom volume. De acordo com Roese (2008), há um aumento do consumo de vinhos, resultando em mudanças na produção e no consumo, já que a principal mudança é condicionada à preferência dos consumidores. Ou seja, se o os consumidores tivessem o conhecimento de uma IG, talvez dariam preferência para 
esses produtos, aumentando o consumo e, consequentemente, a compra dos supermercados por mais vinhos e espumantes com IG.

Mesmo com conhecimento de que a IG tem o propósito de valorizar os produtos, a partir da pesquisa foi constatado que nenhum supermercado possui um local específico para diferenciar esses produtos. $\mathrm{O}$ valor que o cliente tem de um produto está ligado com a percepção que ele possui do produto. A sensação de estar comprando algo diferenciado faz toda a diferença (COELHO; FOLLMANN; RODRIGUEZ, 2008).

Ainda, é nítida a preferência dos consumidores pelos vinhos importados, e os mais procurados são os chilenos em $100 \%$ dos supermercados entrevistados.

A partir do cenário constatado pela pesquisa, é fundamental desenvolver estratégias de divulgação do conceito de indicações geográficas, pois os consumidores ainda não possuem esse conhecimento. Dessa forma, os vitivinicultores dos Vales da Uva Goethe deveriam realizar parcerias com os supermercados para fazer apresentação dos seus produtos e difundir o conhecimento do que é uma IG para o consumidor. Para Coelho, Follmann e Rodriguez (2008), agrega-se valor a um produto quando ele consegue chamar a atenção de um conjunto de consumidores.

Dessa forma, isso pode se tornar a maneira pela qual os consumidores possam obter mais informações sobre os produtos com registro de IG, uma vez que denota qualidade. Assim, o consumidor poderá optar por vinho ou espumante com IG nacional, como os dos Vales da Uva Goethe, cuja região de produção é bem próxima dos estabelecimentos estudados.

\section{Considerações Finais}

O objetivo principal do presente estudo foi identificar a visão do setor supermercadista em relação aos vinhos produzidos com o registro de Indicação de Procedência dos Vales da Uva Goethe na cidade de Criciúma - SC.

O primeiro objetivo específico da pesquisa foi identificar se o sommelier, ou o responsável do setor de vinho na rede supermercadista, tem alguma percepção do comportamento do consumidor referente à Indicação Geográfica, em conformidade com os resultados obtidos pela pesquisa, identificou-se que todos os sommeliers dos estabelecimentos pesquisados possui o conhecimento do que é uma IG, porém, a maior parte dos consumidores não possuem esse conhecimento.

Também, a partir dos dados da pesquisa, constatou-se que todos os supermercados comercializam vinhos e espumantes com IG, no entanto, a maior parte é de produtos estrangeiros. Ainda, a partir da pesquisa, constatou-se que metade dos supermercados pesquisados comercializam vinhos e espumantes com o selo da Indicação de Procedência dos Vales da Uva Goethe.

O segundo objetivo especifico buscou discriminar os tipos de vinho adquiridos pelos consumidores do setor supermercadista de Criciúma - SC. A partir dos dados, percebeu-se que, em todos os supermercados pesquisados, os consumidores têm preferência por vinhos e espumantes importados, com ou sem IG. Fazendo uma análise do segundo objetivo, pode-se perceber que os vinhos importados predominam no mercado brasileiro devido à baixa barreira de entrada desses produtos, com um preço mais atrativo aos consumidores.

O terceiro objetivo identificou qual é a preferência dos consumidores de vinhos e espumantes do setor supermercadistas de Criciúma - SC. Todos os pesquisados responderam que 
a preferência dos consumidores é por vinhos chilenos. Os vinhos chilenos dominam o mercado brasileiro de vinhos, como mencionado na análise.

Este trabalho buscou identificar se os vinhos e espumantes dos Vales da Uva Goethe estão sendo comercializados nos supermercados de Criciúma - SC e qual a percepção que os sommeliers possuem sobre essa IG. Dessa maneira, ficou evidenciado que, apesar de possuírem produtos com IGs nos supermercados, esse conhecimento fica restrito aos profissionais como os sommeliers e não chega até o consumidor. A IP dos Vales da Uva Goethe está presente em metade dos supermercados pesquisados, no entanto, das cinco integrantes, apenas três vinícolas estão presentes, com destaque para a Vitivinícola Urussanga (Casa Del Nonno). A região deverá difundir o conceito de uma IG para que possa chegar até o consumidor. Os sommeliers deveriam passar noções sobre as indicações geográficas para que o consumidor tenha conhecimento de que se trata de um produto com qualidade.

A IG é um forte atributo para os vinhos e espumantes que concorrem com os importados, como os chilenos, por exemplo, e isso pode ajudar a conquistar uma fatia maior do mercado.

Esta pesquisa tem o propósito de contribuir com os produtores dos Vales da Uva Goethe, pois, a partir dos dados obtidos, esses produtores poderão adotar estratégias de comercialização. Diante do cenário apresentado, acredita-se que este estudo cumpriu com os objetivos propostos, respondendo ao problema de pesquisa: Qual a percepção do setor supermercadista em relação aos produtos com selo da Indicação de Procedência dos Vales da Uva Goethe? Pode-se constatar que os supermercados possuem profissionais que conhecem a IG Vales da Uva Goethe, porém algumas informações não são repassadas ao consumidor de forma que ele entenda que seja um produto de qualidade e que é tão bom quanto os demais.

Como sugestão de pesquisas futuras, sugere-se que nos próximos estudos, se procure aumentar a abrangência da pesquisa nos supermercados da Região Sul de Santa Catarina e no litoral catarinense, a fim de identificar a preferência dos consumidores e quais os estabelecimentos que comercializam vinhos e espumantes dos Vales da Uva Goethe.

Conclui-se que o tema é de bastante relevância para os produtores, pois, a partir dele, os produtores poderão formular novas estratégias de mercado para melhor direcionar a venda de vinhos e espumantes produzidos com a uva Goethe, com agregação de valor e com registro da Indicação de Procedência dos Vales da Uva Goethe.

\section{Referências}

ABRAS - ASSOCIAÇÃO BRASILEIRA DE SUPERMERCADOS. Super nosso investe

R\$ 20 milhões em expansão 2017. [2017]. Disponível em: http://abras.com.br/clipping. php?area $=31 \&$ clipping $=62032$. Acesso em: 5 set. 2017.

ACATS - ASSOCIAÇÃO CATARINENSE DE SUPERMERCADOS. Dados associação. [2017].

Disponível em: http://www.acats.com.br/acatsnovo/index.php/institucional/dados-associacao. Acesso em: 5 set. 2017.

APROVALE - Associação dos Produtores de Vinhos Finos do Vale dos Vinhedos. Indicação

Geográfica. [2017]. Disponível em: http://www.valedosvinhedos.com.br/vale/conteudo. php?view=70\&idpai=132\# null. Acesso em: 22 out. 2017 . 
CASA DEL NONNO. Família. [2017]. Disponível em: http://www.casadelnonno.com.br/familia. Acesso em: 25 set. 2017.

COELHO, L. C.; FOLLMANN, N.; RODRIGUEZ, C. M. T. Agregando valor ao cliente através da integração entre marketing e logística. Admpg gestão estratégica, Ponta Grossa, v. 1, n, p. 129134, 2008.

COMÉRCIO, Diário do. Brasil tem potencial para expandir mercado de vinhos. 2016.

Disponível em: http://www.diariodocomercio.com.br/noticia.php?id=169467. Acesso em: 17 out. 2017.

DAMIAN, M. Plano Estratégico de Marketing para a Vitivinícola Urussanga Ltda. 2006. 112 f. Trabalho de Conclusão de Estagio (Graduação em Administração) - Universidade Federal de Santa Catarina, Florianópolis, 2006.

DUARTE, V. N. Estudo da cadeia produtiva do vinho em Santa Catarina: características e estágio atual. Interdisciplinar - Biotecnologia e Alimentos, Joaçaba, v. 13 n. 1, p. 41-56, janeiro-junho, 2013.

\section{EMBRAPA - EMPRESA BRASILEIRA DE PESQUISA AGROPECUÁRIA. Secretaria de Gestão} Estratégica, 2009.

FAO \& SINERGI - ORGANIZAÇÃO DAS NAÇÕES UNIDAS DA AGRICULTURA E ALIMENTAÇÃO, FORTALECIMENTO DA PESQUISA INTERNACIONAL NAS INDICAÇÕES GEOGRÁFICAS.

Ligando pessoas, territórios e produtos: um guia para promover a qualidade ligada à origem $e$ indicações geográficas sustentáveis. Roma: FAO, 2010. 194p.

GLASS, R. F.; CASTRO, A. M. G. As indicações geográficas como estratégia mercadológica para vinhos. [s.l.]: Embrapa Informação Tecnológica, 2009. Disponível em: https://www. embrapa.br/busca-de-publicacoes/-/publicacao/512617/as-indicacoes-geograficas-como-estrategiamercadologica-para-vinhos. Acesso em: 20 out2017.

HANSEN, P. B.; ROSSI, G. Cadeia de suprimentos - análise de ações estratégicas para manutenção da competitividade: o caso do Vale dos Vinhedos. Gestão e Sociedade, [s.l.], v. 2, n. 4, p. 1-27, 2008. Disponivel em: http://www.diariodocomercio.com.br/noticia.php?id=169467. Acesso em: 12 nov. 2016.

IBRAVIN - INSTITUTO BRASILEIRO DO VINHO. Estudo do mercado brasileiro de vinhos tranquilos e vinhos espumantes - Quantitativo - Oferta. Market analysis, Rio Grande do Sul, p. 154, 2008.

IBRAVIN - INSTITUTO BRASILEIRO DO VINHO. Setor vitivinícola cresce $\mathbf{4 , 6 \%}$ em vendas no primeiro semestre. [2015]. Disponível em: http://www.ibravin.org.br/noticias/278.php. Acesso em: 20 out. 2017.

IBRAVIN - INSTITUTO BRASILEIRO DO VINHO. Abastecimento do mercado de vinhos no Brasil apresenta crescimento de 3\% no primeiro semestre. [2017a]. Disponível em: https:// ibravin.org.br/Noticia/abastecimento-do-mercado-de-vinhos-no-brasil-apresenta-crescimento-de-3no-primeiro-semestre/305. Acesso em: 20 out. 2017.

IBRAVIN - INSTITUTO BRASILEIRO DO VINHO. Panorama do mercado do vinho no Brasil. Wine Intelligence. [2017b]. Disponível em: https://www.ibravin.org.br/admin/arquivos/ivb/1540585243. pdf. Acesso em: 17 out. 2017. 
INPI - INSTITUTO NACIONAL DA PROPRIEDADE INDUSTRIAL. Guia básico de indicação geográfica. [2015]. Disponível em: http:/www.inpi.gov.br/menu-servicos/indicacao-geografica. Acesso em: 11 jul. 2017.

INPI - INSTITUTO NACIONAL DA PROPRIEDADE INDUSTRIAL. Perguntas frequentes Indicação geográfica. [2017]. Disponível em: http:/www.inpi.gov.br/servicos/perguntas-frequentespaginas-internas/perguntas-frequentes-indicacao-geografica. Acesso em: 11 jul. 2017.

KOTLER, P. Administração de marketing: análise, planejamento, implementação e controle. 5. ed. São Paulo: Atlas, 1998.

KOTLER, P.; KELLER, K. L. Administração de marketing. 12. ed. São Paulo: Pearson Prentice Hall, 2006. 750 p.

LAMB, C. W.; HAIR, J. F.; MCDANIEL, C. D. Princípios de marketing. São Paulo: Pioneira Thomson Learning, 2004. 644 p.

LAS CASAS, A. L. Marketing: conceitos, exercícios, casos. 7. ed. São Paulo: Atlas, 2005. 324 p.

MAIORKI, G. J.; DALLABRIDA, V. R. A Indicação Geográfica de produtos: um estudo sobre sua contribuição econômica no desenvolvimento territorial. Interações (Campo Grande), Campo Grande, v. 16, n. 1, p.13-25, jun. 2015. Disponível em: http://www.scielo.br/scielo.php?script=sci_ arttext\&pid=S1518-70122015000100002\&lng=pt\&nrm=iso. Acesso em: 17 out. 2017.

MEU VINHO. Chile lidera mercado de vinhos importados no Brasil e apresenta tendências e novidades no ExpoVinis 2017. Blog. CH2A Comunicação, 2017. Disponível em: https://www. meuvinho.com.br/news/648/chile-lidera-mercado-de-vinhos-importados-no-brasil-e-apresentatendencias-e-novidades-no-expovinis-2017. Acesso em: 17 out. 2017.

NIERDELE, P. A. Compromissos para a qualidade: projetos de indicação geográfica para vinhos no Brasil e na França. 2011. 263 f. Tese (Doutorado Ciências Sociais em Desenvolvimento, Agricultura e Sociedade) - Universidade Federal Rural do Rio de Janeiro, Rio de Janeiro, 2011.

OLIVEIRA, R. S.; WEHRMANN, M. E. S. F. Indicação Geográfica é uma boa alternativa para valorização dos produtos do agronegócio brasileiro. Direito, Inovação e Desenvolvimento: tópicos de propriedade intelectual e concorrência. In: REÚNE ARTIGOS DO XX CONGRESSO NACIONAL DO CONPEDI, Vitória, 2013. Anais [...]. Vitória, v. 2. 2013. Disponível em: http://www.arraeseditores. com.br/media/ksv_uploadfiles/d/i/direito_inovacao_vol_2_1.pdf. Acesso em: 19 out. 2017.

PACHECO, V. Compartilhamento do conhecimento e crowdsourcing interno como estratégia de inovação na empresa varejista supermercadista. 2017. 170 f. Dissertação (Mestrado Desenvolvimento Socioeconômico) - Universidade do Extremo Sul Catarinense, Criciúma, 2017.

PASSERINI, F. Valor agregado e valor percebido no marketing de relacionamento B2B. 2011. Disponível em: http://www.housepress.com.br/blogpress/Valoragregado-e-valor-percebido-nomarketing-de-relacionamento-B2B. Acesso em: 17 abr. 2017.

PINDYCK, R. S.; RUBINFELD, D. L. Microeconomia. 8. ed. São Paulo: Pearson Education do Brasil, 2016. $742 \mathrm{p}$.

PROTAS, J. F. S.; CAMARGO, U. A.; MELO, L. M. R. A vitivinicultura brasileira: realidade e perspectivas. [s.l.]: Embrapa, 2003. 
REIS, F. O. A. O ciclo de vida dos produtos e as estratégias de mercado na gestão de marcas: sandálias havaianas - um estudo de caso. 2007. 47 f. Monografia (Engenharia de produção) Universidade Federal de Juiz de Fora, Juiz de Fora, MG, 2007.

RIBEIRO, A. H. O nicho de mercado: o sucesso através das estratégias. 2005. 38p. Monografia (Especialização em Marketing) - Universidade Cândido Mendes, Rio de Janeiro, 2005.

ROESE, M. O mundo do vinho de cabeça para baixo: as transformações no mercado internacional do vinho e o novo empresariado vinícola. Revista de Sociologia e Política, [s.l.], n. 31, p. 71-83, 2008.

SATO, G. S.; ANGELO, J. A. As exportações brasileiras de vinhos e derivados: início de processo de internacionalização. In: X SEMEAD - SEMINÁRIOS EM ADMINISTRAÇÃO FEA-USP, 2007. Anais [...]. São Paulo, 2007.

SÃO PAULO. Consumo de vinho no Brasil cresce, mesmo com retração na economia. Em 3 de agosto de 2015. Disponível em: http://www1.folha.uol.com.br/comida/2015/08/1663417consumo-de-vinho-no-brasil-cresce-mesmo-com-retracao-na-economia.shtml. Acesso em: 15 mar. 2017.

SMITH, W. Diferenciação de produtos e segmentação de mercado como estratégias alternativas de marketing. The Journal of Marketing, [s.l.], v. 21, n. 1, p. 3-8, 1956.

TAVARES, Mauro Calixta; AFONSO, Tarcisio; LOCATELLI, Ronaldo Lamounier. Segmentação de mercado, diferenciação de produtos e a perspectiva da antropologia do consumo. Revista Gestão \& Tecnologia, Pedro Leopoldo, v. 11, p. 122, jan.-jun. 2011.

TERROIRS. Panorama do consumo de vinhos no Brasil. 2016. Disponível em: http://www. terroirs.com.br/panorama-do-consumo-de-vinhos-no-brasil/. Acesso em: 12 nov. 2016.

TERUCHKIN, S. U. As estratégias empresariais para os vinhos finos no Brasil e no Uruguai: uma análise comparada. 2003. 304 p. Tese (Doutorado) - Universidade Federal do Rio Grande do Sul, Rio Grande do Sul, 2003, 304p.

UNIVERSOAGRO. Qualidade do vinho Goethe faz consumidores baterem nas portas das vinícolas. 2014. Disponível em: http:/www.uagro.com.br/editorias/agricultura/outros/2014/07/25/ qualidade-do-vinhogoethe-faz-consumidores-baterem-nas-portas-das-vinicolas.html. Acesso em: 19 out 2017

VALES DA UVA GOETHE. Histórico. Urussanga, 2013. Disponível em: http://www. valesdauvagoethe.com.br/ipvug.php?id=1. Acesso em: 24 abr. 2016.

VÁZQUEZ, B. L. Publicidad emocional: estrategias creativas. Madrid: ESIC, 2007.

VELLOSO, C. Q. Indicação geográfica e desenvolvimento territorial sustentável: a atuação dos atores sociais nas dinâmicas de desenvolvimento territorial a partir da ligação do produto ao território (um estudo de caso em Urussanga, SC). 2008. 166 p. Dissertação (Mestrado em Agroecossistemas) - Universidade Federal de Santa Catarina, Centro de Ciências Agrárias, Florianópolis, 2008.

VIEIRA, A. C. P.; PELLIN, V. O uso do instituto das indicações geográficas como instrumento de promoção do desenvolvimento territorial rural: o caso dos Vales da Uva Goethe Brasil SC. In: 20 APDR CONGRESS - RENAISSANCE OF THE REGIONS OF SOUTHERN EUROPE. 20 APDR Congress - Renaissance of the regions of southern Europe: Evora, 2015. Anais [...]. Evora, 2015. 
VIEIRA, A. C. P.; WATANABE, M.; BRUCH, K. L. Perspectivas de desenvolvimento da vitivinicultura em face do reconhecimento da Indicação de Procedência dos Vales da Uva Goethe. Revista Geintec., São Cristovão, UFS, 2012. Disponível em: http://www.revistageintec.net/index.php/revista/ article/view/49/125. Acesso em: 7 maio 2016.

\section{Sobre os Autores}

\section{Arthur Coan}

E-mail: arthur_coan@hotmail.com

Bacharel em Administração.

Endereço profissional: Av. Universitária, n. 1.105, Universitário, Criciúma, SC. CEP: 88806-000.

\section{Adriana Carvalho Pinto Vieira}

E-mail: dricpvieira@gmail.com

Doutora em Desenvolvimento Econômico.

Endereço profissional: Rua Henrique Thielen, n. 1.150, apto 02, Ponta Grossa, PR. CEP: 84015-650.

\section{Michele Domingos Schneider}

E-mail: michele.schneider@unesc.net

Mestre em Desenvolvimento Socioeconômico.

Endereço profissional: Av. Universitária, n. 1.105, Universitário, Criciúma, SC. CEP: 88806-000.

\section{Julio Cesar Zilli}

E-mail: michele.schneider@unesc.net

Mestre em Desenvolvimento Socioeconômico.

Endereço profissional: Av. Universitária, n. 1.105, Universitário, Criciúma, SC. CEP: 88806-000. 